Ssciendo

10.2478/abcsj-2021-0018

\title{
Violence, Innocence and Redemption in Irvine Welsh's Chemical Mythos
}

ANDREI-CĂLIN ZAMFIRESCU

Babeș-Bolyai University, Cluj-Napoca, Romania

\begin{abstract}
Scottish author Irvine Welsh has crafted an internally cohesive cosmology, grounded in mapping a somewhat loosely defined "chemical generation" that helped spearhead a personal brand of anti-Thatcherite counterculture (with an especially heavy focus on the marginalized, disgruntled and boisterous youths of Edinburgh). Examining some of the writer's most recent and lesser-known works, my essay will argue that a series of archaic mythical patterns, symbols and cosmological coordinates can be shown to guide a large number of the axioms that Welsh employs to refine his own vision of a modern, emergent mythos.
\end{abstract}

Keywords: Irvine Welsh, comparative mythology, emergent mythology, archaic cosmology, altered states of consciousness, ritual initiation, chemical generation

The reemergence of mythical patterns in modern transgressive fiction has drawn critical attention in relation to the ostentatious eschatologies constructed by authors such as Bret Easton Ellis or Chuck Palahniuk. The main goals of transgressive literature are generally thought to consist of the intentional deconstruction (via the deployment of unmitigated or hypertrophied vulgarity) of various alienating or dehumanizing aspects of consumerism and its maladaptive cultural outgrowths. In the case of Scottish writer Irvine Welsh's particular brand of riotous fiction these budding tropes of social dissent and rebellion have fully flourished into a shared universe, bearing all the general characteristics of a cohesive mythos. Its features range from a flurry of cosmological axioms, to 
patterns of personal liberation and interpersonal communion, to the pitfalls and tragedies of isolated stories depicting moral corruption and youthful folly. My primary aim is to evoke a series of structural similarities between Welsh's universe and archaic mythological systems. Aiming to prove that the Scottish author's more recent fiction serves as a conduit for the reemergence of these types of mythemes (albeit in a mutated form, shaped by the particular speculative horizons of Welsh's cosmology), my study attempts to not only describe the process through which some of these patterns emerge, but also to showcase the way through which the author's shared universe ends up imprinting its own ethos upon them.

A blend of sexuality and a vast array of soteriological techniques provides a set of recurring concerns, as well as a corollary panoply of grotesque representations, in the later works of Irvine Welsh. A Decent Ride, a novel which remains predominantly galvanized by a single, overarching stylistic pattern, and which can be read as a structurally inferior appendix to the vulgar hilarity of the Trainspotting saga (or, for that matter, of Glue) ventures further than its predecessors in its investigation of violence, sexual addiction, national Scottish pride or intercultural relationships. The theme of sexuality foregrounds its function as sublimation of trauma, and subsequent projection as violence. Terry Lawson, its hero, reemerges after his debut in Glue (and his later infiltration as a tertiary agent in the Trainspotting sequel Porno), and redirects the narrative course towards his own narrow slant of subjectivity. Now middle-aged, albeit only physically, Welsh's veteran foil proves the passage of time has altered neither his main interests, nor his choleric, pigheaded nature and his yet immature spunk. Three subplots are concerned with the monolithic personality of Terry, while another, more atypical narrative thread focuses on the wanderings of a young local with learning disabilities, Jonty. Terry, now working full-time as a cab driver in his city of origin, forms an unlikely (and ambivalent) camaraderie with Ronald Checker, an American business magnate forged according to the cardinal traits and stereotypes of WASP culture and transatlantic superficiality.

The pair become unlikely partners in a venture spearheaded by the U.S. celebrity. Checker's monomaniacal crusade comprises a series of 
golf matches, played out against another capitalist potentate for the conquest and possession of a bottle of rare whiskey (of the fictional Bowcullen Trinity variety, indigenous to Scotland and boasting only three extant bottles). A second narrative layer focuses on Lawson's impotence, medically induced following the diagnosis of a heart condition with possibly lethal consequences. The loss of libido (or, more exactly, the obligation to inhibit its prowess through pharmaceutical means) turns into a catastrophic event, bearing all the outward signs of a katabasis that pushes our hero to the extreme limits of existential angst. Finally, the attempt to unearth the identity of Terry's unknown father, connected to another possible family relation (the timid Jonty) completes the narrative triptych. The entire Jonty strand - mainly developed as a subplot intended as comic relief - constitutes a grotesque and symbolically inverted imitation of the hierogamy depicted in Welsh's previous novel, The Sex Lives of Siamese Twins. Advantageously endowed in his sexual anatomy, yet deprived of a fully functioning psychic apparatus, Jonty inadvertently precipitates the downfall of his relationship with his partner, Jinty.

His long-standing significant other suddenly succumbs to a drug overdose, with the distraught young man as the sole witness (initially prepared to deny, and then determined to conceal his own involvement in the event). His peregrinations along the rural landscape of Scotland encapsulate virtually every typology of abusive sexual relations. Constructed as divergent, yet symmetrically aligned entities, Terry and Jonty's destinies become intertwined, as it dawns upon the former that they might, in fact, be stepbrothers. Throughout the novel, the author's tone never departs from his early - now matured - brand of vulgar hilarity: the volume's darker corners, harboring a few of Welsh's favorite controversial topics, are not allowed to fester as sober reflections (as in the case of Crime, Trainspotting or Marabou Stork Nightmares). On the contrary, black comedy, absurdity and ethical indifference emerge as the defining characteristics of certain instantiations of Scottishness. For example, the text is structurally divided according to the phases of a devastating natural phenomenon: the occurrence of a hurricane which had assailed the country in 2011. Quickly dubbed "Hurricane Bawbag" ["scrotum"] by local slang (Welsh, A Decent Ride 54 et pass.), the 
harrowing event is greeted by the populace as a minor disturbance, dissolving in irrelevance and failing to stimulate any sort of proactive or defensive efforts.

Intentionally inserted as a way of anchoring the text in recent history, the brief time period allotted to the hurricane's rampage paradoxically reinforces an older mark of Welsh's mythos - an adherence to a personal brand of timeless escapism. The text repeatedly grounds the event within the confines of a particular history which will serve as a temporal reference point for all ulterior episodes (occurring over what is giddily described as "the post-Bawbag era"). The locals' indifference towards a major event turned into an axis of recent historyechoes the passive and sterile fermentation of historical consciousness harbored by the youngsters of Trainspotting. According to Welsh, younger generations are all too keen on relinquishing their cultural history and heritage, a cynical gesture made possible by the farcical tone adopted by their culture. Mark Renton's individual dismissal of his ethnic identity is paralleled by a more ample, cross-cultural equivalent, suggested in $A$ Decent Ride by the general lack of concern for safety and the systematic taunting practiced by the Scots. Within Scottish culture, this humorous and hypertrophied self-flagellation is turned into a means of refiguring community. The facade of conscious self-deprecation is, on the other hand, abandoned the moment it is proffered from the outside, and replaced with a sudden revitalization of ethnic and national pride. Scottish identity seems to perpetuate itself by virtue of a constantly maintained inner conflagration. The more restrictive cultural confines of the marginalized, young and damned inhabitants of Welsh's cosmology host the same inclinations, although their ballistic scope is narrower: the "chemical generation's" inherent spirit of rebellion rises not against subcultural sources intruding from the outer rims of alterity (which are actually quite often welcomed wholeheartedly), but in open conflict against everything that local, autochthonous tradition supports.

Terry's growing animosity towards Ronald Checker (spurred on not just by a web of cultural differences, but especially by class disparity) is granted an unexpected pseudo-patriotic stance during the narrative climax. Terry helps the American win the precious bottle of whiskey and then 
proceeds to steal it away and bury it in the grave of "Post" Alec: a minor character from Glue and a former mentor figure, revealed in A Decent Ride to be Lawson's biological father. As a symbolic artifact of ethnic identity, the bottle of alcohol is awarded a halo of almost numinous radiance through the funeral ceremony enacted by Lawson and the accompanying Jonty (Welsh, A Decent Ride 457). An attempt to decipher the significance of the gesture against the background of the precise topography inscribed in Welsh's fictional cosmology casts light on a particularly complex mythos. Firstly, the episode deals with the resurfacing of broken lineage, a quasi-mythical trope developed by Welsh in some of his earlier works. In the vein of Danny Skinner from The Bedroom Secrets of the Master Chefs, Roy Strang from Marabou Stork Nightmares or Bruce Robertson from Filth, Terry is haunted by his phylogeny. The tragic, agonistic overtones of Roy's condition derive from the inescapable certainty of belonging to the "Strang clan," which assimilates his genetic particularities to a nefarious stigma (he bemoans having faced oppression at the hands of other characters because he has inherited the typical physiognomy of his relatives, pejoratively dubbed "the Strang look"). Similarly, Bruce Robertson's mysterious ancestry ends up constituting the central mechanism through which his ethical deformity is explained. Contributing to the narrative climax of Filth, the final touches to Bruce's retroactive portrait produce the revelation that his biological father was a notorious criminal, whose acute psychopathic tendencies he has inherited in a dormant variation (and whose recent awakening is suggested to have occurred as the novel's troubling plot is unfolding). Like Terry, Danny Skinner does not know his genetic lineage: existential frustration and indeterminacy permeate both cases, but as young men the two characters follow antipodal pathways. Lawson's hedonistic satyriasis is counterbalanced by the introverted intellectualism cultivated by Danny. While sexuality and extroversion guides Terry's existence towards a telluric desire for communion, Skinner's confinement within his own inner battlements, the presupposition of his ontological superiority (through his accumulation of knowledge as a self-taught erudite), the obsessive compulsion to discover his origins, and his 
deepening alcoholic habits encourage the physical manifestation of the hex that drives the conflict between him and his rival, Brian Kibby.

The grand revelation that puts an end to Terry's katabasis in $A$ Decent Ride comes up as a consequence of a self-conscious act of contemplation. He realizes that his final telos is not so much the fulfillment of an insatiable libido, but rather the desire to make himself desirable, and thus, to be accepted and loved. Yet again, Terry's willingness to open himself up to alterity finds its dark symbolic counterpart in Danny's all-consuming egotism (which threatens to turn him into an agent of apeiron, of the kind that Bruce Robertson ends up embodying). These existential pathways are given legitimacy (as in the case of most characters crafted by Welsh) through an artery of biochemical reality that treads a fine ethical line between the moderate, liberating use of narcotics and addictive abuse. Depending on the mythical reading angle through which the text is approached, this chemical, organic ritualism gains either causal, or symptomatic undertones.

Seen as post-apocalyptic tribal agents, Welsh's heroes entertain a symbiotic communion with their addictions and experiment freely with the transformation of states of consciousness, primarily out of an escapist impetus: from this point of view, heroin, sexual stimulation, junk food, alcohol and any other substance or intensely somatic experience play a compensatory part that nevertheless hypertrophies existential alienation (granted an ontology diametrically opposed, yet just as damaging, to that of its primary cause). A neo-mythical perspective (approaching substance consumption as a property of the passive component of mythical fortitude inscribed in the texts), casts light on the functional proximity of all methods of organic self-regulation to the use of certain substances in archaic ritualism. The cultural functions of the dream states in ecstatic trances, induced through various chemical means in order to trigger and prolong mystical insight, the intoxicated enthusiasm of those Vedic authors who had ingested the enigmatic Soma, and many other such examples of traditional techniques of consciousness transformation (facilitated through both external and internal means) share the same soteriological purpose with Welsh's heroes. 
Both archaic ceremonial practices and the recreational use and abuse of substances detectable in Welsh's cosmology are rooted in the fusion of two ontological horizons. The ultimate existential coordinates of human consciousness - helped along more or less by certain natural propensities - converge, through the assimilation of external substances, with the drugs' own set of terminal coordinates. Insofar as we can speak of an inorganic or vegetable Umwelt, its specificity confronts consciousness as a wall of ontological opacity, rendering all attempts to reflexively construct a Weltanschauung null and void. Human consciousness, in its most usual instances of day-to-day function, appears just as much to be configured within certain limiting parameters. The cooperation between the (often inorganic) Umwelt of the absorbed substances and the inner life that has produced and normalized the standard Weltanschauung of man (subsumable under the tenets of "naive realism"), has been crucial in the act of expanding - or deforming - the accessible empirical horizon of the latter.

Amplifying the penchant for imaginative speculation and solipsistic reflection by inserting allogenic elements within an individual's organic geometry has often resulted in the production of innovative paradigms. Several decades of accumulating scholarly work have emphasized the generative importance of "chemical" communions. At the end of the 19th century, a mythologist such as J.G. Frazer (incidentally, also of Scottish origin), still associated the archaic variants of creative imagination with simplistic (magical and puerile) proclivities to pass incorrect judgments on the workings of the natural world. Later theorists challenged such positivist claims and initiated a gradual understanding of the direct impact that chemical interactions with allogenic substances could have had on the construction of primordial cosmologies and mythical systems. Early on, pioneering psychoanalysts such as Jung drew attention to the "primitive" affinity for erasing the border between the inner world of the psyche and the outer world of nature, which has since been thoroughly documented. The cultural effects of such an erasure are often manifested as fractured versions of the individual self (also depicted in a negative light by the early founders of nineteenth-century anthropology). The character of Bruce Robertson in Filth, with his partitioned personality, represents an 
incidental reemergence of the manifold self. The tapeworm that infests him and philosophizes inside his intestinal tract is a grotesque, degraded version of the "bush-soul," or animal double, to be found in Jung's description of archaic cultures: "Among such people, whose consciousness is at a different level of development from ours, the 'soul' (or psyche) is not felt to be a unit. Many primitives assume that a man has a 'bush soul' as well as his own, and that this bush soul is incarnate in a wild animal or a tree, with which the human individual has some kind of psychic identity" (Jung 24).

The related tangent of Welsh's critique of historical Scotland provides an alternative interpretation of Bruce's schizophrenia as the effect of traumatic origins. From this angle, both his doubled persona, and the set of natural and social factors which have molded the antihero's early years can be equated with the spasms of contemporary national consciousness: "Written in the years leading up to the Scottish Parliament's resumption in 1999, one can read Filth and the hyperbolic characterization of Bruce Robertson not as a premonition for the kind of Scotland - 'a compulsively autocratic power' - that Welsh perceives as being born through increasing national sovereignty, but rather one which must be authoritatively rejected for a new, culturally diverse, aspirant nation to emerge. This is personified in Bruce's conflicted self, one which cannot accept the injustices of its birth and childhood" (Munro 44). These divergent avenues of interpretation need not be mutually exclusive. In its mythical mode, the main ontological border constructed by archaic patterns of thought does not, itself, entail a clear separation between the psychological and natural spheres. Rather, a halving of the world is enacted almost always between the poles of an immediate, existential reality and another, dreamlike space which must be approached and breached by the individual using a completely different cognitive arsenal. This second domain is the "dream time" of the Australian aboriginals, "mythic time" or the "spirit world." The voyages of the individual into these realms are mainly acted out through the inner mechanisms of consciousness, modified in many cases through the insertion of allogenic factors. The infrastructure of Welsh's grand cosmology presupposes a similar method of employing one's mental resources, mobilized into 
action towards the end goal of escapism, exploration or selftranscendence. A crucial difference between the variation of organic cohabitation typical of archaic communities and that of Welsh's protagonists consists largely of the level of self-awareness ascribed to the central actors. In the case of the modern characters, an additional set of axioms (modifying both the end goal and the way symbiotic experiences are processed) provides another factor of differentiation. Welsh's grand geography is also informed by a secondary undercurrent: the tension between a harsh, idiosyncratic representation of locality and its reverberation in the greater vista of an empiricism that does not subside when ignored. Similarly restrained to the geographic confines of their immediate surroundings, many archaic tribes could enact their practices of self-transcendence whilst having the luxury of ignoring what lay beyond the pale of their small-scale societies. As opposed to them, the larger socio-economic context in which Welsh's dissident mavericks are immersed cannot be ignored. Therefore, transformations of consciousness never result in an ethos of vertical mobility. Material reality, although repugnant and abused, cannot be left behind: as Alan Riach reminds us, "the fiction of Irvine Welsh offsets the mimetic representation of reality by combining two apparently contradictory modes: an immediate vernacular voice, ostensibly an authentic representation of location specific speech, and a narrative where unpalatable basic realities of economic and bodily imperatives are paramount" (Riach 35-36).

Welsh's mythos appears to be fundamentally calibrated by the annihilation of the metaphysical. Both the entrance into a version of "mythic time" and the chemically triggered exploratory incursions are strongly corporeal. His characters are all too aware that the transformations of consciousness that they embark on do not ship them off to an unexplored, alien dimension. The cardinal dynamic which in an archaic mode of thought would have meant transgressing the boundaries of the world into a communion with a superstructured reality coexistent with the data of the everyday, is pushed, in Welsh's case, into the abyss of an infrareality that can produce only the impression of a transpsychological autonomy, but which is always retrospectively evaluated as a mere hallucinatory experience. For the rationalist historians of the 
archaic functions of myth, the discovery and exploration of non-empirical realities by primitive holy figures served, primarily, to accomplish a more mundane, utilitarian purpose: man, beset by uncontrollable natural events and his own vulnerability, fashioned himself countless fictional spaces to sublimate the horror of his condition, transgress his destructible nature and, eventually, offer himself the illusion of control and power over those forces and events which threatened him with annihilation.

In his study The Eternal Ones of the Dream, Géza Róheim documents an example of such a figure (Róheim 191), an Australian aboriginal magician who sublimates his own somatic dimension, abolishing its vulnerability and gaining an assurance of his subsistence by virtue of this process. After undergoing a ceremonial sequence of chants, the holy man announces that his own innards have been transubstantiated into precious gems. The ontological crux of vulnerability, the fragile and organic core of man, is thus shaped into a nucleus of corporeal fortitude, to which is added the extra layer of its new, mineral aesthetic. This fundamentally utilitarian perspective on the origin and function of myth has been, of course, contested and supplemented by more recent theories. In the case of Welsh's fiction, however, the techniques of chemical communion seem to be exclusively oriented towards this end. As neoprimitive or eschatological agents, his protagonists see in these methods of consciousness alteration an illusory revolt against the perceived abominable fabric of their environment defined as a cultural, rather than a natural topography.

A case that sets itself apart from Welsh's treatment of either rebellious subcultures or the overarching culture of bourgeois conformity is provided by the pseudo-tribal cult of the perpetually irate and belligerent football hooligans. The humor with which these groups of modern-day berserkers and their eruptions of spontaneous brutality are painted is counteracted by the underlying meaninglessness of their violence (as well as the socioeconomic background that spurs them into action). Their description is modeled on the appearance and conduct of a wild hunt, of the kind that is so widespread and documented in a multitude of European folk traditions. As with their mythical counterparts' passage through random swathes of countryside terrain, death, suffering and pain 
are the main consequences of the vandalism and beatings the marching football hooligans engage in: "Actually, the cohort that descends from the air to the canopy of the trees, and then on the earth, is a heterogeneous gathering of hideous and grotesque individuals, led by an enigmatic Devil. The living that are found to be in a state of capital sin are captured en route. The next day, at the corner of some crossroads or other, one can find their disfigured corpses" (Dontenville 158, my translation).

In its most extreme instances, Welsh's brand of chemical soteriology, intended to counteract the historical or genetic determinations of one's environment, degenerates into acts of self-destruction. The archaic temporary visits to the spirit realms become fully conscious explorations of one's interior physiology. For Welsh, the body represents the final bastion of individual freedom, containing, in its epicenter, the cardinal virtue of his thought: authenticity. While during primitive ecstatic trances a diaphanous iteration of being was sent out to map an unfamiliar external realm, the pharmaceutical ceremonies abounding in Welsh's cosmology are directed mainly towards a reorganization of their own senses of self and metacognition. In both cases, the basic data external to the psyche are suppressed or interpreted in symbolic terms. For Welsh, they almost always function as a merely temporary reprieve, that of active inhibitors, placed at the forefront of an encroaching reality or, although often misleading, that of ensured survival. This is best illustrated by Welsh's re-utilization of one of his first antiheroic figures.

In The Blade Artist, Franco Begbie is for the first time ushered into the role of leading man. Placed at the tail end of the Trainspotting series' chronology, this volume retains an individual, standalone status as an isolated character study extracted from the continuity of the microhistory that has fueled Welsh's writing career. In the context of the interconnected web that forms the common ground of his fiction, the stasis of The Blade Artist points to yet another radical shift in the direction of a metanoia. Some of Welsh's earlier "redeemed" figures include Mark Renton, arguably the centerpiece of the Trainspotting saga's first volume or, to a lesser extent, Carl Ewart, the budding music enthusiast who would later become "DJ N-Sign," and whom we first meet in Glue. However, neither example embodies a radical shift in the moral alloy of these two 
protagonists. As opposed to Begbie, Renton and Ewart remain fundamentally aligned with a sort of natural benevolence and willingness to engage amiably with the rest of society. Initially, following his early iterations as the unofficial mascot of Trainspotting and of Welsh's mythos, Franco is a domineering, atypical individual, incompatible not only with bourgeois culture, but also with the subcultures that he most often immerses himself in. As in Trainspotting, this self-imposed isolation is echoed by his open disdain for the vices of his companions. He is guided by his own set of self-destructive habits of a more visceral nature than the heroin in which Renton and the other youths indulge in. Ironically, Begbie's more marginal addictions end up partially conforming to the very axioms of self-abuse perpetuated by his archenemy, the conservative and normative culture that seeks to absorb him: "Up until now, I've omitted any discussion of Renton's fourth mate, Francis Begbie, because unlike the others he is an alcoholic. That is, he abuses the bourgeoisie's drug of choice, and to Renton he himself is like an addiction. This sociopathic foil doesn't do drugs, he 'does people,' which is to say that he tyrannizes and brutalizes them" (Cardullo, 161). His conscience is constantly defined by the fermentation of a sort of radical dualism, but his penchant for occasional bouts of extreme violence seems to have grown tawdry during his prolonged absence from his homeland. As is the case with so many other agents in Welsh's cosmology, physical distance from one's place of origin metaphorically turns into a numinous, fundamentally adaptive and regenerative escape. The Californian setting in which Begbie has been naturalized in the interim between The Blade Artist and his last appearance in Porno resembles an Avalon-like haven of physical and spiritual restoration. However, the gnawing worm of social and sexual dysfunction insists on resurfacing even in these warmer climates, as novels such as Crime or The Sex Lives of Siamese Twins attempted to showcase.

By virtue of his own metanoia, Franco inhabits the typology embodied by Bruce Robertson, except only on a formal level, and which Ray Lennox, the hero of Crime, will gradually claim as his own, following his own travails in Florida. Ray and Bruce, as classic illustrations of the maladaptive student-teacher duo, are brought together 
in an amalgam of ethical ambiguity and virtues that result from an intense, laborious work of self-initiation. Both men act as representatives of the law, and, thus, as agents of the superimposed cultural order. On a mythical level, successfully maintaining the continued function of this legislative body would confirm their status as tribal paragons of the local customs of which they are a part. In this vein of interpretation, the utility of Lennox and Robertson's actions would overlap the position of the archetypal "purgers" or "purifiers of evil", acting in accordance with the dicta of their cultural paradigm. Concerning the passive aspect of mythical fortitude exhibited by Welsh's fiction, their roles also overlap professionally with those of archaic hunters.

In a traditional tribal community, augmenting an individual's status with the attributes of a specific social role (along with a proper sense of a solidified identity) may only be set in motion by a ritualistic process which actualizes the individual and extracts him from the nonhuman anonymity of childhood - a process which typically culminates in a formalized rite of passage. Those who preside over the ceremony and confirm the ascension of the neophytes to their new condition are almost always the elder keepers of the law, fixed at the top of tribal hierarchy as figures of sacred authority for the entire community. In keeping with the reenacted logic of this archaic kind of cosmology, Lennox and Robertson would have had to have been extracted from their initial infantile status and then transmogrified into fully established protectors (as well as into valid, particularized members of the tribal collective). Welsh's mythos, however, operates in accordance with its own set of cosmological axioms, a central one positing that assimilation into the dominant culture is tantamount to losing one's authenticity or soul. As a consequence, not only do Lennox and Robertson commit an act of hybris by partaking in the rituals and cadences imposed on them by an abusive cultural model, but their preference for conformity also arises against the backdrop of immaturity - more exactly, a specific type of puerile nonconformity which counterproductively estranges them from the culture they are attempting to integrate in, triggering their eventual ostracization. Considering the fact that immaturity and innocence play a crucial role, as prime principles, in the existential permutations of most of Welsh's 
protagonists, the transplantation of the two Lothian lawmen at the margins of their environment's ethical coordinates will come as a natural consequence of a set of traumatic, primordial events, geared especially towards these same cardinal properties.

In these cases, early trauma results in loss of innocence, accompanied by the impossibility of ever reaching functional maturity, and determines all the future deontological mutations undergone by the two men. As mythical cynegetic entities, their immersion in an antipodal set of decisive ritual initiations during their childhoods will conform to an isomorphic pattern of regression and stagnation. Firstly, there is the case of Bruce Robertson, tragically tied to the inexorable force of hereditary degeneration, often presented in Welsh's prose as a biological stigma indicating a future moral downfall. An unlikely readerly empathy with Bruce's fatal destiny may result from additional biographical details. His romantic attachment, as a child, to a classmate with physical disabilities, along with his ulterior vehement rebuttal of her affection, to avoid being ostracized by his peers, provides an early dysfunctional erotic experience. Another childhood event, more brutal this time, conditions Ray Lennox's own sexuality behavior, in a similar maladaptive fashion. In Crime, young Lennox recounts the harrowing experience of exploring an abandoned tunnel situated on the outskirts of the city, in the company of a friend, and falling victim to a group of pederasts who lurked in a curved area of the tunnel's midsection, completely immersed in darkness (Welsh, Crime 283).

The protagonist's trauma informs his later development less in terms of direct personal experience, and more through an interposed layer of failed altruism, regret and self-hatred, directed at his own vulnerability and perceived cowardice (entrenched in the memory of abandoning his friend to particularly brutal treatment at the hands of their assailants in the tunnel; it is revealed that Ray managed to narrowly escape the ordeal through a stroke of luck). Coincidentally, the very same kind of tunnel will serve a similar sepulchral function at the end of Bruce Robertson's own downward spiral into insanity. Finding himself in the final stages of lethal psychosis, accelerated during the narrative climax to the point of complete dissociation from either reality or any other pretense of internal 
cohesion, Robertson stumbles upon the underground passage whose external and symbolic features overlap with the setting of Lennox's ordeal. Having reached the same midpoint in the tunnel's curve in which the two luminous awnings of the passage are hidden away and replaced with absolute darkness, Bruce abandons any remaining resistance and hope, collapsing completely in an interior void paralleled by the tangible, outer abyss that envelops him.

His subsequent suicide, calibrated as an antiapotheosis which restores an illusory sense of ontological equilibrium, can be interpreted not just as an act of self-annihilation, but also as a malignant form of selfpreservation - namely, of his fractured sense of self, only now perceived as an authentic manifestation of his identity (albeit only in its current monstrous state, goaded into tumescence by an oppressive cultural backdrop). As Samantha Cartaino points out:

In this moment, he is no longer blaming himself or feeling guilty; he is just moving forward. He finally understands that his made-up identity does not fit him and his real identity - which is comprised of several elements due to his schizophrenia - is different from what he has seen in others around him. Instead of death being a negative action against himself, Bruce kills himself as a way to preserve his identity in a world that works so hard to make him identify as one being. (23)

For Lennox, on the contrary, the loss of innocence coincides with a moment of failed growth into adulthood, a transitory moment that will mutilate him until his redemptive tribulations in Crime help reconfigure his teleological axis.

As part of a traditional rite of passage, the symbolic act of devouring a neophyte is often enacted by a monstrous entity and typically precedes the simulation of spiritual death, which is followed by rebirth to a new sense of identity and tribal belonging, as a full-fledged member of society. Mircea Eliade gives an account of the essential moments of this interstitial moment, emphasizing the mystical phylogeny entailed by the figure who symbolically ensures the correct finalization of the process. These figures are often identified as various zoomorphic entities who take on the role of a devouring ancestor, acting towards the benefit of the neophyte and his individuation. It is significant that in Welsh's cosmology 
- and this transpires especially clear in Crime - this zoological aspect is preserved as a signal foreshadowing the particular type of predatory initiation triggered in their victims by the abusive characters:

The ceremony always commences by separating the neophyte from his family and secluding him in the woods. The symbol of Death is already present: the woods, the jungle, the darkness all represent the nether realm, 'Hell'. In some places it is believed that a tiger arrives to whisk the candidates off on its back and takes them all the way to the forest: the beast represents the mythical Ancestor, the initiation master, who leads the adolescents to Hell. (Eliade 126, my translation) ${ }^{\mathrm{ii}}$

Within Welsh's inverted cosmic coordinates, the very same process serves to reiterate a radically opposite metamorphosis: the arrest of growth and ascension to adulthood, perpetuated ad infinitum through the solipsistic mechanisms of self-blame and regret, provides the sole mythical function of the darkened tunnel. In both instances in which it is described, the anonymous passage is vested with a chthonian iridescence. The gradual decline of all light sources, leading towards the epicenter of deathly stillness and the encroaching darkness lying in wait, the subtle hints of its almost sentient voraciousness, the phantomlike apparitions of the nefarious assailants, impossible to trace during the entirety of Lennox's future Lothian career, all these properties will help paint a picture of the tunnel as the final embankment of an inframaterial Hades.

The ad-hoc manifestation of the disruptive entities is structurally reminiscent of the summoning spells and invocations pertaining to the apparition of infernal forces from some forsaken underworld, spontaneously let loose upon reality from a realm of inscrutable murk and just as quick to return to it once their duty has been accomplished. That which, traditionally, would have represented a place of mere illusory terror, a herald of a fundamentally benign transformation, is morphed into a realm of oblivion and death, poetically isomorphic with the Biblical "outer darkness where there is weeping and gnashing of teeth" (Matthew 25:30). Setting the tone of Welsh's cosmology, the dark passage described in Crime and Filth is constructed as the metaphorical nadir of the world. True to the biochemical precepts of the author's mythos, the land of the damned is not projected beyond any metaphysical horizon, but is instead 
encrusted in an opaque, materialist sediment, assembled a posteriori according to the most basic rules of sensuousness. The consequences of entering its core will be dichotomous, simultaneously signaling Bruce's definitive damnation and the first bitter outbursts of a future heroic telos for Ray.

For Robertson, the synchronization of his inner and outer voids only comes as a last confirmation of his condition as an autonomous avatar of the darkness that greets him in the tunnel, all devouring in the confines of the microhistory in which he is permitted to act and finally self-destruct. His communion with the darkness constitutes a formal reincorporation into a pre-cosmogonic flow that had already been assimilated at all levels of his psyche. While deeply scarring, Lennox's journey into the tunnel ultimately paves the way towards a path of moral redemption and, more importantly, to the status of genuine protector of the innocence of others.

It is in this grand cycle, which bears a symbolic resemblance to various traditional forms of rites of passage or ceremonies of initiation, that characterizes the interlocking paths of all of Welsh's major protagonists. Whether ending in damnation (as is the case of Bruce Robertson or Roy Strang), or in redemption (as can be observed, albeit partially, in the soteriological travails of Terry Lawson or Ray Lennox), these trajectories seem intrinsically imbued with various "material" means of ushering those caught in their flow to their eventual fates. Always heralding a great ontological shift, these patterns of moral awakening or perdition remain firmly entrenched in a brutal reality where, although it preserves only the mere vestiges of archaic patterns of self-transcendence and ascension, they are nevertheless still as potent. Displaying the alluring trace of numinous physicality, these patterns remain one of the cornerstones of Welsh's mythos - and of the distilled experiences of his chief audience or "tribe," namely the bawdy and sublime "chemical generation." 
Notes:

i "En fait, la cohorte descendant des airs sur la cime des arbres, puis à même la terre, est un ramas hétéroclite de gens hideux et grotesques, entraînés par un Diable énigmatique. Sont happés au passage les vivants en état de péché mortel. On trouve le lendemain, au coin de quelque carrefour, leurs cadavres défigurés" (158).

ii "Ceremonia începe întotdeauna prin despărțirea neofitului de familie și retragerea sa în pădure. Există de pe acum un simbol al Morții: pădurea, jungla, întunericul reprezintă lumea de dincolo, 'Infernul.' În unele locuri se crede că vine un tigru care îi poartă pe candidați în spinare pînă în pădure: fiara îl întruchipează pe Strămoșul mitic, Dascălul inițierii, care îi conduce pe adolescenți în Infern" (126).

\section{Works Cited}

Cardullo, Bert. "Fiction into Film, or Bringing Welsh to a Boyle." Literature/ Film Quarterly 25.3 (1997): 158-162.

Cartaino, Samantha. "'Same Rules Apply:' Analyzing Image and Identity in Irvine Welsh's Filth in Relation to the Scottish Independence Movement." Faculty Curated Undergraduate Works, Paper 23. Philadelphia: Arcadia UP, 2015.

Dontenville, Henri. La France Mythologique - Travaux de la société de mythologie française. Paris: TCHOU, 1966.

Eliade, Mircea. Sacrul și profanul. Trans. Brîndușa Prelipceanu. București: Editura Humanitas, 2000.

Jung, Carl Gustav. Man and his Symbols. New York: Anchor P, 1988.

Munro, Robert. "Irvine Welsh and the Adaptation Industry: Filth, a case study." International Journal of Scottish Theatre and Screen 7.2 (2014): 31-56.

Riach, Alan. "The Unnatural Scene: The Fiction of Irvine Welsh." The Contemporary British Novel. Eds. James Acheson and Sarah C. E. Ross. Edinburgh: Edinburgh UP, 2005. 35-47.

Róheim, Géza. The Eternal Ones of the Dream. New York: International UP, 1945.

Welsh, Irvine. A Decent Ride. London: Vintage, 2016.

---. Glue. London: Jonathan Cape, 2001.

---. Marabou Stork Nightmares. London: Jonathan Cape, 1995.

---. Porno. London: Jonathan Cape, 2002.

---. The Bedroom Secrets of the Master Chefs. London: Vintage, 2007.

---. The Blade Artist. London: Vintage, 2017.

---. The Sex Lives of Siamese Twins. London: Jonathan Cape, 2014.

---. Crime. London: Vintage, 2009.

---. Filth. London: Vintage, 2013.

---. Trainspotting. London: Vintage, 2013. 